\title{
As medidas de enfrentamento à exploração do trabalho infantil no Brasil: forças em luta
}

\author{
Soraya Franzoni Conde \\ Universidade Federal de Santa Catarina (UFSC)
}

As medidas de enfrentamento à exploração do trabalho infantil no Brasil: forças em luta

Resumo: O objetivo deste artigo é refletir sobre as soluções encontradas para o problema da exploração do trabalho infantil no Brasil. Para isso, apresenta as atuais políticas públicas destinadas à eliminação do trabalho infantil no país - legislação, políticas de transferência de renda e de escolarização - e revela, por meio de dados do IBGE, a persistência da exploração do trabalho infantil. Procura, assim, mostrar que, embora as políticas públicas para a erradicação do trabalho infantil sejam importantes, o problema persiste, pois as medidas para enfrentá-lo não atingem as suas origens.

Palavras-chave: Trabalho infantil. Políticas públicas. Transferência de renda. Escola.

\section{Measures to Confront the Exploitation of Child Labor in Brazil: forces in struggle}

Abstract: This article reflects on measures taken to end the exploitation of child labor in Brazil. It presents the current public policies designed to eliminate child labor in the country including laws, income transfer programs and educational programs - and uses census data to reveal the persistence of child labor. It also shows that although public policies for eliminating child labor are important, the problem persists because the measures used to confront it do not reach the roots of the problem.

Keywords: Child labor. Public policies. Income transfer. School. 


\section{Introdução}

Este artigo, valendo-se de parte das pesquisas feitas para a tese de doutorado em Educação (CONDE, $2012)^{1}$ sobre a relação entre a escola e a exploração do trabalho infantil na fumicultura catarinense, tem como objetivo refletir sobre as soluções encontradas, através da implementação de medidas institucionais, para enfrentar o problema da exploração do trabalho infantil no Brasil, na atualidade.

O debate acerca das soluções para o problema do trabalho infantil é polêmico. Se, para alguns, a questão está na exploração humana, inaugurada com a emergência do modo capitalista de produção, para outros, decorre de desajustes sociais possíveis de serem resolvidos por meio de reformas legislativas e políticas e do avanço da escolarização entre a classe trabalhadora. Sem perder de vista as atuais discussões, o texto procura apresentar e refletir sobre as soluções para o problema que procedem principalmente de programas sociais com cunho socioeducativo.

O texto traz reflexões, primeiramente, quanto às diversas soluções emanadas dos órgãos oficiais para resolver o problema do trabalho infantil e, na sequência, aponta como se apresenta essa realidade em dados, sua dimensão e suas características.

Em termos metodológicos, percorre a legislação existente sobre a exploração do trabalho infantil no Brasil, as atuais políticas de transferência de renda e de alongamento da escolarização e os dados do Instituto Brasileiro de Geografia e Estatística (BRASIL, 2006). Além disso, revisa a bibliografia existente sobre a temática e os clássicos estudos sobre trabalho e educação da classe trabalhadora (FERRARO, 2009; HOBSBAWN, 2007; MÉSZÁROS, 2001, 2005; OLIVEIRA, 2003; SMITH, 1989).

\section{As medidas para o enfrentamento da exploração do trabalho infantil}

As medidas implementadas para enfrentar o problema do trabalho infantil no Brasil decorrem de concepções reformistas descoladas da ordem totalitária do sistema capitalista de produção. Assim, conferem à escola, às políticas públicas e à legislação a tarefa de erradicá-lo sem transformar as bases da sociedade capitalista. No âmbito das ações políticas internacionais, são desenvolvidas legislações e metas para a erradicação do trabalho infantil no mundo. Após o final da Primeira Guerra Mundial, em 1919, criamse a Organização Internacional do Trabalho (OIT) e, em 1939, o Fundo das Nações Unidas para a Infância (Unicef) para tratar das políticas relacionadas à infância, nos países pobres. A criação da OIT e da Unicef é realizada para separar decisões financeiras internacionais das metas que agem sobre os efeitos contraditórios dos problemas criados pelo sistema capitalista de produção. As decisões econômicas e os rumos do capitalismo internacional permanecem sob o controle do Banco Mundial (BM) e da Organização Mundial do Comércio (OMC). Com isso, os problemas como o trabalho infantil aparecem separados da exploração decorrente do sistema econômico capitalista.

\section{A via da legalidade no Brasil}

A legislação brasileira é considerada uma das mais avançadas no mundo sobre o trabalho infantil, regulamentando-o na Constituição Federal, na Consolidação das Leis do Trabalho (CLT) e no Estatuto da Criança e do Adolescente (ECA). A primeira legislação brasileira data da Velha República. Segundo Aguiar (2004) e Pilotti e Rizzini (1995), os primeiros indícios de resolução legal desse problema datam de 1891, quando foi aprovado o Decreto n. 1.313, que instituiu a fiscalização de todos os estabelecimentos industriais da Capital Federal e definiu a idade mínima para o início no trabalho: 12 anos. A legislação também definia que, de 8 a 12 anos, permitia-se o trabalho na condição de aprendiz, desde que não colocasse em risco a vida dos pequenos trabalhadores. Em 1919, com a criação da OIT, o Brasil ratifica várias convenções, entre as quais destacam-se a Convenção 05/1919 - idade mínima de 14 anos para o trabalho na indústria - e a Convenção 06/1919 - proibição do trabalho noturno de menores na indústria. No ano de 1927, como decorrência de pressões políticas internacionais, foi formulado o Código dos Menores, que limitou em seis horas o trabalho diário, com uma hora para repouso, e proibiu as atividades insalubres para menores de 18 anos. A primeira Consolidação das Leis do Trabalho, formulada em 1943, redefiniu a idade mínima para 14 anos; e, no ano de 1988, a Constituição Federal manteve essa idade.

O Estatuto da Criança e do Adolescente (BRASIL, 1990) permite o trabalho infantil aprendiz entre $14 \mathrm{e}$ 16 anos. No ano de 1998, a Emenda Constitucional n. 20 altera a idade mínima para 16 anos e permite o trabalho aprendiz entre 14 e 16 anos. Em seguida, são ratificadas as Convenções da OIT n. 138 (idade mínima 
para o trabalho) e n. 182 (piores formas de trabalho infantil) e efetuados vários programas de governos e ações de entidades não governamentais (BRASIL, 1999, 2002).

Uma das questões legislativas polêmicas relativas ao trabalho infantil na atualidade diz respeito à permissão do trabalho entre 14 e 16 anos na condição de aprendiz e à definição das "piores formas" de trabalho infantil. A permissividade legal da contratação do aprendiz e os incentivos fiscais ao contratante tornam o emprego de adolescentes mais vantajoso do que o de adultos. Dessa forma, a legislação brasileira, ao regulamentar, acaba incentivando a contratação de menores aprendizes para tarefas simples que não necessitam de um trabalhador qualificado adulto. A lei acaba apenas proibindo as piores formas de trabalho infantil, ou seja, aquelas que degeneram precocemente o trabalhador e, assim, comprometem a reprodução futura do sistema de produção.

$\mathrm{Na}$ atualidade, encontram-se em discussão as Propostas de Emendas à Constituição (PEC) n. 18 e n. 35, de 2011, que almejam reduzir a idade mínima do trabalho aprendiz no Brasil de 14 para 12 anos. As PECs contradizem a Convenção n. 18 da OIT, da qual o Brasil é signatário, em que a idade mínima para o trabalho não pode

Desde 1996, o Governo

Federal brasileiro tem

desenvolvido programas de

transferência de renda com o

objetivo de solucionar os

principais problemas sociais do

país, entre os quais se destaca

o trabalho infantil. ser inferior ao término da escolaridade obrigatória (15 anos no caso brasileiro, quando se entende que, se não tiver reprovação, o adolescente conclui o ensino fundamental).

A proposta de diminuição da idade mínima representa uma tentativa de avanço das forças mais conservadoras do liberalismo nacional que visam diminuir, tanto quanto possível, a instrução pública estatal desses adolescentes, inserindo-os logo no trabalho produtivo, algo altamente vantajoso aos contratantes, além de concorrente desleal do desemprego adulto, tendo em vista o salário e os incentivos fiscais. A PEC em discussão tem como pressuposto que a educação desses adolescentes será voltada para as práticas efetivas de trabalho e de suas necessidades reais. Por isso é importante garantir que frequentem a educação básica, assim como Adam Smith (1989) já admitia no século 18, preparando-os para uma maturidade capaz de suportar a jornada de trabalho.

Consideramos que o limite dos marcos legais está na ausência de crítica ao processo de exploração do trabalho, típico do sistema capitalista. Os essenciais, como indica Mészáros (2005), referem-se aos motivos que impedem a contratação dos desempregados no lugar das crianças e dos adolescentes. Ao discutir piores formas e idade mínima, deixamos de solucionar os problemas necessários ao desenvolvimento pleno de todos os seres humanos, pois as outras formas de trabalho infantil permanecem socialmente aceitas, ou ainda, consideradas educativas.

Para Klein (2010), a questão legal do trabalho infantil é complexa e tangencia o problema contraditório do trabalho na sociedade capitalista, onde ocorrem modos inaceitáveis de intensificação da jornada que prejudicam o desenvolvimento da criança e os modos de trabalho considerados necessários para a formação do ser humano. Essas contradições, para a autora, intrínsecas ao trabalho, são expressas na legislação que proíbe o trabalho insalubre, mas o permite na condição de aprendiz. Dessa forma, ignora-se o debate acerca da dimensão alienadora, exploradora e degeneradora do trabalho submetido à lógica do capital, revelando o problema do trabalho infantil, associado às condições insalubres e à maldade dos empregadores. Abandonada a questão do trabalho produtor de mais-valia, resta definir formas de regulamentá-lo por idade e condições de trabalho.

\section{As políticas de transferência de renda e de ampliação da escolarização no Brasil}

Desde 1996, o Governo Federal brasileiro tem desenvolvido programas de transferência de renda ${ }^{2}$ com o objetivo de solucionar os principais problemas sociais do país, entre os quais se destaca o trabalho infantil.

O Programa de Erradicação do Trabalho Infantil (PETI) é criado como parte das políticas desenvolvidas no âmbito dos países signatários da OIT para atender crianças de cinco a 15 anos, por meio da concessão de uma bolsa. As bolsas são destinadas para famílias com renda per capita mensal de cerca de R\$120 e com situação de trabalho infantil. Para receberem a bolsa, as crianças necessitam frequentar a escola.

Ferro e Kassouf (2005), ao analisarem a eficácia desse programa, percebem que as crianças atendidas pelo PETI não deixam de trabalhar, mas diminuem, em duas ou três horas, a jornada semanal de trabalho, visto que passam a frequentar a escola num período e a trabalhar em outro. Assim, as crianças que só trabalhavam passam a estudar e aquelas que já estudavam complementam a renda familiar. Embora as crianças estejam na 
escola - em virtude de o recebimento da bolsa depender da frequência escolar - e como não é exigido que deixem de trabalhar, o programa acaba não atingindo o objetivo de solucionar o problema do trabalho infantil. A erradicação, à que o programa se propõe, é delegada ao futuro e à possibilidade de quebra do ciclo da pobreza por meio da qualificação escolar.

Pincelli (2005) analisa o programa "O futuro é agora", desenvolvido desde 1998 pelo Sindicato da Indústria do Fumo da Região Sul do Brasil (Sindifumo) e pela Associação dos Fumicultores do Brasil (Afubra) como decorrência do "Pacto do Setor Fumageiro pela Prevenção e Erradicação do Trabalho infantil na Produção de Fumo". O pacto é decorrente de pressões políticas internacionais que responsabilizam as empresas fumageiras pela existência de crianças trabalhando em propriedades integradas de cultivo de fumo. Na atualidade, os três estados da região Sul do Brasil aderiram ao programa, que busca a conscientização social das famílias acerca dos efeitos do trabalho infantil e obriga cada agricultor a prever no contrato:

1) respeito aos direitos da criança;

2) não exploração do trabalho infantil;

3) manutenção de seus filhos na escola.

O programa também auxilia na estruturação de escolas para os filhos dos fumicultores e desenvolve projetos que buscam estimular os direitos da criança, o trabalho no campo, o empreendedorismo, o desenvolvimento rural e a sustentabilidade. Conforme a análise que a autora realizou das aulas e do material didático, fornecidos pela empresa, o ensino é voltado ao trabalho do agricultor, à sua instrumentalização técnica e à aquisição de conhecimentos gerais, o que é altamente favorável à manutenção das formas integradas de trabalho na fumicultura. As novas técnicas de plantio exigem que o agricultor tenha maior escolarização para que, por exemplo, possa estar conectado à Internet para receber orientações da empresa e, assim, reduzir os custos de viagens dos instrutores. Dessa forma, o programa aproveita o espaço escolar para qualificar o agricultor do futuro, conforme os interesses da empresa integradora.

A autora ressalta que, com o slogan da responsabilidade social, empresas como a Souza Cruz garantem competitividade e vendem uma imagem de "empresa amiga da criança" com produtos diferenciados nacional e internacionalmente. No fundo, o programa desenvolvido funciona como marketing empresarial, pois o consumidor europeu (principal mercado do fumo brasileiro) prefere produtos com uma imagem responsável. Além disso, a empresa recebe incentivos fiscais para o desenvolvimento do programa, o que evidencia que, no fundo, o Estado brasileiro é quem financia a formação voltada aos interesses comerciais da iniciativa privada, confirmando a importância da tríade Estado, Capital e Trabalho para a manutenção das estruturas sociais vigentes. Essa constatação, mais uma vez, evidencia a atualidade das propostas liberais de educação que, desde o século 18, defendem a instrumentalização técnica dos filhos dos trabalhadores com a aprendizagem de conhecimentos gerais (na época: saber ler, escrever e contar).

$\mathrm{Na}$ atualidade, poderíamos adicionar informática e inglês, de acordo com as necessidades da produção comercial, estejam no campo ou na cidade. Conforme Mészáros (2001, p. 121), as políticas públicas não estão acima da esfera produtiva, pois o Estado é parte intrínseca do capital:

O Estado moderno pertence à materialidade do sistema do capital e corporifica a necessária dimensão coesiva de seu imperativo orientado para a expansão do trabalho excedente. É isso o que caracteriza todas as formas conhecidas do Estado que se articula na estrutura da ordem sociometabólica do capital. Precisamente porque as unidades econômicas reprodutivas do sistema têm um caráter incorrigivelmente centrífugo - caráter que há longo tempo na história tem sido parte integrante do incomparável dinamismo do capital, ainda que, em certo estágio de desenvolvimento, ele se torne extremamente problemático e potencialmente destrutivo -, a dimensão coesiva de todo sociometabolismo deve ser constituída como uma estrutura separada de todo metabolismo. [...]. Entretanto, o princípio estruturador do Estado moderno em todas as formas - inclusive as variedades pós-capitalistas - é o seu papel vital de garantir e proteger as condições gerais de extração da mais-valia do trabalho excedente.

Seguindo a mesma perspectiva teórica citada, Oliveira (2003) afirma que o papel do Estado é institucionalizar o jogo social, fixando regras e meios para a redistribuição de recursos entre classes capitalistas. Dentro das contradições inerentes à lógica que sustenta a acumulação de capital, cresce o trabalho infantil, aumenta o número de ambulantes e de subempregados, erroneamente chamados de informais. Esses trabalhadores compõem o trabalho abstrato virtual, argumenta o autor. As "políticas piedosas tentam treinar e qualificar essa mão-de-obra, num trabalho de Sísifo, jogando água em cesto, acreditando que o velho e o bom trabalho com carteira voltará" (OLIVEIRA, 2003, p. 143).

O fato de as políticas de transferência de renda, a legislação e a obrigatoriedade da escolarização não terem alcançado a erradicação do trabalho infantil (AGUIAR, 2004; FERRO; KASSOUF (2005) tem sido 
debatido entre assistentes sociais, sociólogos, educadores e promotores de justiça. A escola em período integral é apontada como possível solução ao problema, pois tende a manter a criança na escola durante todo o dia enquanto os pais trabalham.

Desde 2008, as primeiras escolas brasileiras começaram a oferecer educação integral com jornada ampliada. Já em janeiro de 2010, o Decreto n. 7.083 (BRASIL, 2010), buscando articular políticas voltadas à implementação de educação integral no Brasil, dispõe sobre o "Programa Mais Educação", cuja finalidade é contribuir na melhoria da aprendizagem e da permanência de alunos matriculados em escolas públicas de educação integral que tendem a se desenvolver articuladas aos saberes locais de cada comunidade. Conforme Goulart (2008), durante muito tempo o debate sobre a escola integral foi deixado de lado no Brasil, porque se entendia que seria necessário dobrar a estrutura escolar para o atendimento. Mas agora, com a possibilidade de integrar a formação com a comunidade na perspectiva da "cidade educadora", é possível ampliar o tempo e o espaço escolar com custos reduzidos, aproveitando o que os territórios possuem.

Para Maricato (2006), a defesa do território, do bairro e do local é uma armadilha que visa esconder a política econômica internacional, que determina grande parte dos problemas vividos nos locais periféricos. Esse localismo contradiz as formas como as políticas locais são determinadas globalmente. As taxas de juros do Brasil, por exemplo, são definidas pelo Banco Central. Suas reuniões secretas com atas indecifráveis são orientadas pelo FMI, que, por sua vez, defende a independência do Banco Central em relação ao Estado brasileiro.

Assim, percebemos que a proposta de educação integral ganha fôlego não somente para atender às demandas das famílias trabalhadoras que necessitam de um local seguro para os filhos ficarem ou para eliminar o trabalho infantil, ou ainda, para combater os velhos problemas educacionais (evasão e repetência), mas para alavancar iniciativas liberais de educação do indivíduo, tendo por princípio educar o cidadão pobre, com parcos recursos, nos limites das desigualdades do capitalismo.

\section{A persistência do problema}

Não obstante a legislação e as políticas públicas de erradicação do trabalho infantil, os dados da Pesquisa Nacional por Amostra de Domicílios (PNAD, 2006) mostram que 5,1 milhões de crianças e adolescentes (entre 5 e 18 anos) ainda trabalham no Brasil, o que representa 11,5\% da população na faixa etária correspondente. Das crianças e dos adolescentes ocupados, 41,4\% estão em trabalhos agrícolas; proporção que chega a $62,6 \%$ entre 5 e 13 anos.

De acordo com dados do IBGE (BRASIL, 2006), entre as crianças e os adolescente que trabalham no Brasil, na faixa etária entre 5 a 13 anos, há predominância do trabalho não remunerado, atingindo a taxa de $57 \%$. Nesta mesma faixa etária, as atividades para o próprio consumo atingem $21 \%$, enquanto $15,1 \%$ ocupamse do trabalho doméstico e $6,8 \%$ trabalham por conta própria.

Já na faixa entre 14 e 15 anos, predominam os trabalhadores não remunerados, atingindo 41,5\%, enquanto empregados e trabalhadores domésticos chegam a 41,3\%, seguidos de trabalhadores para o próprio consumo, $10 \%$, e trabalhadores por conta própria, $7 \%$. Conforme a idade avança, percebe-se que aumenta o número de trabalhadores domésticos e diminui o número de não remunerados e de trabalhadores voltados para o próprio consumo.

Segundo o IBGE/PNAD (BRASIL, 2006), 49,4\% das crianças e dos adolescentes entre 5 e 17 anos de idade no Brasil exercem afazeres domésticos. Essa atividade é destinada com maior frequência e intensidade às meninas. Ainda na faixa etária de 5 a 17 anos, pouco mais de um terço, ou seja 36,5\%, dos homens cuidam dos afazeres domésticos, enquanto que a proporção é de $62,6 \%$ para as mulheres - situação que se repete em todas as faixas etárias, a partir de 10 a 18 anos.

A frequência à escola ou à creche cresce de acordo com o aumento do rendimento mensal domiciliar per capita. Enquanto que para as crianças e os adolescentes de 0 a 17 anos de idade, com rendimento mensal domiciliar per capita de menos de um quarto de salário mínimo, a taxa de frequência à escola ou à creche é de 69,3\%, para aqueles moradores em domicílios, com rendimento per capita de dois ou mais salários mínimos, a taxa de frequência atinge $86 \%$.

Esses dados, revelam que o acesso à escola e a opção pelo trabalho infantil não dependem do nível cultural e da escolaridade familiar, mas, sobretudo, das condições materiais da família (BRASIL, 2006).

Como podemos observar, através da análise desses percentuais fornecidos pelo IBGE, a frequência à escola não é suficiente para não trabalhar. Embora existam grandes contingentes de crianças que trabalham e deixam de estudar, a maior parte das crianças que trabalham frequenta uma instituição escolar: 95,5\% (5 a 13 anos), 84,2\% (14 ou 15 anos) e 70,8\% (16 ou 17 anos). Também é possível observar que, com o avançar da idade, a taxa de escolarização diminui e o número de crianças que trabalham aumenta. 


\section{Considerações finais}

Ao analisarmos as medidas de enfrentamento ao problema do trabalho infantil no Brasil, percebemos que a maioria das políticas sociais parte do pressuposto de que a escolarização é a solução para a pobreza (motivo do trabalho infantil), pois, qualificados e escolarizados, os filhos da classe trabalhadora podem encontrar emprego e conseguir um melhor rendimento no futuro. Como decorrência desse raciocínio, uma bolsa é concedida à criança trabalhadora para que ela frequente a escola. A escola em tempo integral também aparece como uma solução cujo intuito é fazer com que as crianças cursem as disciplinas curriculares obrigatórias em um período e desenvolvam atividades extracurriculares em outro, afastando-se do trabalho.

Observamos que a legislação proíbe o trabalho de crianças, a escola torna-se obrigatória e as políticas de transferência de renda tentam resolver o problema ignorando suas origens estruturais. Não obstante, a exploração do trabalho infantil persiste, como atestam os dados do IBGE apresentados no texto.

As políticas públicas não estão acima da esfera produtiva, pois o Estado é parte intrínseca do capital, atuando em sua ordem sociometabólica (MÉSZÁROS, 2001). Nesse sentido, as políticas de Estado garantem e protegem a exploração da mais-valia. Embora as políticas públicas para a erradicação do trabalho infantil sejam importantes, segundo Mészáros (2001), elas necessitam atuar de modo a criar condições para o próprio desaparecimento. Se o problema do trabalho infantil surge com a exploração do mais valor, é preciso atuar para a eliminação dessa premissa.

\section{Referências}

AGUIAR, A. de. Programa de Erradicação do Trabalho Infantil/PETI de Florianópolis: percepção dos adolescentes egressos. 2004. Monografia (Graduação em Serviço Social) - Universidade Federal de Santa Catarina, Florianópolis, 2004.

BRASIL. Senado Federal. Decreto Legislativo n. 178. Aprova os textos da Convenção 182 e da Recomendação 190 da Organização Internacional do Trabalho. Brasília, 1999.

. Presidência da República. Lei n. 8.069, de 13 de julho de 1990. Dispõe sobre o Estatuto da Criança e do Adolescente e dá outras providências. Brasil, 1990.

. Presidência da República. Decreto n. 3.877, de 24 de julho de 2001. Institui o Cadastramento Único para Programas Sociais do Governo Federal. Brasil, 2001.

. Presidência da República. Decreto n. 4.134, de 15 de fevereiro de 2002. Promulga a Convenção n. 138 e a Recomendação n.146

da Organização Internacional do Trabalho (OIT) sobre Idade Mínima de Admissão ao Emprego. Brasil, 2002.

. Instituto Brasileiro de Geografia e Estatística-IBGE. PNAD-Pesquisa Nacional por Amostra de Domicílio 2006. Disponível

em: <www.ibge.gov.br>. Acesso em: 10 mar. 2013.

. Presidência da República. Decreto n. 7.083, de 27 de janeiro de 2010. Dispõe sobre o Programa Mais Educação. Brasília, 2010.

CONDE, S. F. A escola e a exploração do trabalho infantil na fumicultura catarinense. 2012. 192 p. Tese (Doutorado em Educação)

- Centro de Ciências da Educação, Universidade Federal de Santa Catarina, Florianópolis, 2012.

FERRARO, A. Liberalismo e educação ou porque o Brasil não podia ir além de Mandeville. Revista Brasileira de Educação, Rio de Janeiro, v. 14, n. 41, p. 308-325, maio/ago. 2009.

FERRO, A. R.; KASSOUF, A. L. Avaliação do impacto do Programa Bolsa-Escola sobre o trabalho infantil no Brasil. Pesquisa e Planejamento Economico, Rio de Janeiro, v. 35, n. 3, p. 417-444, 2005.

GOULART, M. A. A intersetorialidade da educação integral. In: MEC/TV ESCOLA. Salto para o futuro. Boletim XVIII, ano 13, p. 1719, Brasília, 2008.

HOBSBAWN, E. J. A era das revoluções. Tradução de Maria Tereza Lopes Teixeira e Marcos Penchel. São Paulo: Paz e Terra, 2007. KLEIN, L. R. Trabalho alienado versus trabalho como princípio educativo: contradição não resolvida no trato do trabalho infantojuvenil. In: CONGRESSO PAULISTA DE EDUCAÇÃO MÉDICA 7, 2010, São Paulo. Anais... São Paulo, 2010.

MARICATO, E. Posfácio. In: DAVIS, M. Planeta favela. São Paulo: Boitempo, 2006, p. 209-224.

MÉSZÁROS, I. Para além do capital. Tradução de Paulo Cezar Castanheira e Sérgio Lessa. São Paulo: Boitempo, 2001.

. A educação para além do capital. Texto publicado a partir de conferência na abertura do Fórum Mundial de Educação, realizado em Junho de 2004, em Porto Alegre. Tradução de T. Brito. São Paulo: Boitempo, 2005.

OLIVEIRA, F. Crítica à razão dualista: o ornitorrinco. São Paulo: Boitempo, 2003.

PILOTTI, F.; RIZZINI, Irene. A arte de governar crianças. Rio de Janeiro: Instituto Interamericano del Nino; Editora Universitária Santa Úrsula; Anais Editora, 1995.

PINCELLI, A. C. S. Trabalho infanto-juvenil na fumicultura e responsabilidade social empresarial: o discurso da Souza Cruz. 2005. Dissertação (Mestrado em Sociologia Política) - Universidade Federal de Santa Catarina, Florianópolis, 2005.

SMITH, A. Inquérito sobre a natureza e as causas das riquezas das nações. Tradução de Teodora Cardoso e Luís Cristóvão de Aguiar. Lisboa: Fundação Calouste Gulbenkian, 1989. (v. 1). 


\section{Notas}

1 Esse artigo é parte da tese de doutorado em Educação intitulada A escola e a exploração do trabalho infantil na fumicultura catarinense, defendida em abril de 2012 no Programa de Pós-Graduação em Educação da UFSC, orientada pela professora doutora Célia Regina Vendramini a quem agradecemos as inúmeras contribuições para este trabalho.

2 São eles: Benefício de Prestação Continuada (BPC), Programa de Erradicação do Trabalho Infantil (PETI), Programa de Renda Mínima (PRM), “Bolsa Escola”, Programa Bolsa Alimentação, Agente Jovem, Auxílio Gás, Previdência Rural. Em 2001, por meio do Decreto n. 3.877 (BRASIL, 2001), é instituído o Cadastro Único dos Programas Sociais do Governo Federal, objetivando a focalização das políticas públicas para a população considerada mais pobre. O "Cartão do Cidadão" aparece no mesmo período como forma de unificação, coordenação e controle da população atendida pela denominada Rede de Proteção Social. Desde 2003, o Bolsa Família unifica os programas Bolsa Escola, Auxílio Gás e Bolsa Alimentação, e o Fome Zero passa a ser desenvolvido.

\section{Soraya Franzoni Conde}

sorayafconde@gmail.com

Doutorado em Educação pela Universidade Federal de Santa Catarina (UFSC) e Universidade de Lisboa Professora no Centro de Ciências da Educação da UFSC (CED-UFSC)

UFSC - Centro de Ciências da Educação

Campus Universitário Prof. João David Ferreira Lima

Trindade

Florianópolis - Santa Catarina - Brasil

CEP: 88040-970 